\title{
ASK1 is essential for endoplasmic reticulum stress-induced neuronal cell death triggered by expanded polyglutamine repeats
}

\author{
Hideki Nishitoh, ${ }^{1}$ Atsushi Matsuzawa, ${ }^{1}$ Kei Tobiume, ${ }^{1}$ Kaoru Saegusa, ${ }^{1}$ Kohsuke Takeda, ${ }^{1}$ Kiyoshi \\ Inoue, ${ }^{2}$ Seiji Hori, ${ }^{2,3}$ Akira Kakizuka, ${ }^{2,3,4}$ and Hidenori Ichijo ${ }^{1,4,5}$ \\ ${ }^{1}$ Laboratory of Cell Signaling, Graduate School, Tokyo Medical and Dental University, Bunkyo-ku, Tokyo 113-8549, Japan; \\ ${ }^{2}$ The Fourth Department, Osaka Bioscience Institute, Osaka 565-0874, Japan; ${ }^{3}$ Kyoto University Graduate School of \\ Biostudies, Kyoto 606-8501, Japan; ${ }^{4}$ Core Research for Evolutional Science and Technology, Japan Science and Technology \\ Corporation
}

Expansion of CAG trinucleotide repeats that encode polyglutamine is the underlying cause of at least nine inherited human neurodegenerative disorders, including Huntington's disease and spinocerebellar ataxias. PolyQ fragments accumulate as aggregates in the cytoplasm and/or in the nucleus, and induce neuronal cell death. However, the molecular mechanism of polyQ-induced cell death is controversial. Here, we show the following: (1) polyQ with pathogenic repeat length triggers ER stress through proteasomal dysfunction; (2) ER stress activates ASK 1 through formation of an IRE1-TRAF2-ASK1 complex; and (3) ASK1 ${ }^{-/-}$primary neurons are defective in polyQ-, proteasome inhibitor-, and ER stress-induced JNK activation and cell death. These findings suggest that ASK1 is a key element in ER stress-induced cell death that plays an important role in the neuropathological alterations in polyQ diseases.

[Key Words: ASK1; JNK; endoplasmic reticulum stress; polyglutamine disease; ubiquitine-proteasome system; apoptosis]

Received March 18, 2002; revised version accepted April 11, 2002.

Expanded polyglutamine (polyQ) is now known to be the cause of nine inherited neurodegenerative disorders, including Huntington's disease (HD), spinobulbar muscular atrophy (SBMA), dentatorubral-pallidoluysian atrophy (DRPLA), and six spinocerebellar ataxias (SCAs 1, 2, $6,7,17$, and SCA3/Machado-Joseph disease [MJD]). PolyQ fragments derived from the full-length protein associated with each of the polyQ diseases have been shown to form intracellular aggregations and to produce toxic effects (Kakizuka 1998; Paulson et al. 2000) as observed in cultured cells and transgenic animals overexpressing polyQ proteins (Ikeda et al. 1996; Jackson et al. 1998; Warrick et al. 1999; Kazemi-Esfarjani and Benzer 2000; Satyal et al. 2000) and in postmortem brain of polyQ diseases patients (DiFiglia et al. 1997; Paulson et al. 1997). Genetic and molecular studies suggest that polyQ causes alteration of gene expression, abnormal protein interactions, alteration of proteolysis, and activation of caspases and protein unfolding (Paulson et al.

${ }^{5}$ Corresponding author.

E-MAIL ichijo.csi@tmd.ac.jp; FAX 81-3-5803-0192.

Article and publication are at http://www.genesdev.org/cgi/doi/10.1101/ gad.992302.
2000; McCampbell and Fischbeck 2001; Nucifora et al. 2001). However, the causal relation between these cellular events and the pathogenesis has not been elucidated.

Recent studies suggested that polyQ fragments with pathogenic repeat lengths are colocalized with various molecular chaperons and proteasome components (e.g., HSP70, HSP40, 20S, and 19S) (Waelter et al. 2001) and impair the function of the ubiquitine-proteasome systems (UPS) (Bence et al. 2001; Jana et al. 2001; Waelter et al. 2001). Because UPS normally control the quality of proteins by degradation, the blockage of UPS by polyQ might result in the accumulation of misfolded proteins that are produced at the normal protein turnover. Importantly, elevated levels of chaperones and proteasome subunits were shown to mitigate the toxic effects of polyQ (Warrick et al. 1999; Kazemi-Esfarjani and Benzer 2000). These observations suggest a functional link between proteasomal dysfunction and accumulation of misfolded proteins in the context of polyQ-induced neurotoxicity (Orr 2001; Sherman and Goldberg 2001). However, it is unclear how polyQ-induced proteasomal dysfunction and protein unfolding can be molecularly converted to neuronal cell death. 
Accumulation of unfolded proteins within the endoplasmic reticulum (ER) lumen induces ER stress, and ER stress has been recently implicated in human diseases such as Alzheimer's disease (Katayama et al. 1999; Nakagawa et al. 2000), Parkinson's disease (Imai et al. 2001) and diabetes mellitus (Delepine et al. 2000; Harding et al. 2001). Initial mediators of ER stress responses are ERresident type I transmembrane serine/threonine protein kinases, PERK and IRE1; accumulation of unfolded proteins in ER induces oligomerization-dependent autophosphorylation of these kinases (Bertolotti et al. 2000; Liu et al. 2000), and thereby initiates cytoplasmic signal transduction. It was shown recently that activated IRE1 on ER membrane recruits TNF receptor-associated factor 2 (TRAF2) and thus activates c-Jun amino-terminal kinase (JNK) (Urano et al. 2000b). In addition, overexpression of IRE1 induced apoptosis in HeLa cells (Iwawaki et al. 2001). Nevertheless, a direct target of IRE1-TRAF2 complex in the ER stress-induced JNK-signaling pathway is unknown.

We have shown previously that the mammalian mitogen-activated protein kinase (MAPK) kinase kinase (MAPKKK) termed apoptosis signal-regulating kinase (ASK1) directly interacts with TRAF2 and constitutes a TRAF2-ASK1-SEK1/MKK4-JNK cascade in TNF signaling (Nishitoh et al. 1998). ASK1 is activated in response to various stimuli through distinct mechanisms and relays those signals to the stress-activated protein kinases, JNK and p38 (Nishitoh et al. 1998; Saitoh et al. 1998; Tobiume et al. 2001). Overexpression of ASK1 induces apoptosis in various cells through mitochondria-dependent caspase activation (Ichijo et al. 1997; Saitoh et al. 1998; Hatai et al. 2000). Recently, we have shown that by deleting ASK1 in mice, TNF- and $\mathrm{H}_{2} \mathrm{O}_{2}$-induced apoptosis are suppressed in $A S K 1^{-/-}$cells (Tobiume et al. 2001). These observations suggest that ASK1 plays essential roles in stress-induced apoptosis.

In the present study, we investigated the role of ASK1 in the pathogenesis of polyQ diseases. PolyQ fragments with pathogenic repeat length inhibited proteasomal activity and thereby induced ER stress. Activated IRE1 by polyQ induced the TRAF2-ASK1 complex formation that led to JNK activation. We show that primary neurons derived from $A S K 1^{-/-}$mice were resistant to ER stress-, proteasome dysfunction-, and polyQ-induced JNK activation and cell death. ASK1 thus mediates proteasome dysfunction- and ER stress-induced neuronal cell death, which plays an important role in the neuropathological alterations in polyQ diseases.

\section{Results}

\section{PolyQ triggers ER stress}

The molecular mechanism by which expanded polyQ induces neuronal cell death is not fully understood. To investigate the causal relation between polyQ, ER stress, and neuronal cell death, we first examined whether polyQ induces ER stress as assessed by the band-shift analyses of ER-resident transmembrane kinases, IRE1 and PERK. We have previously established PC12 cell lines that express normal length polyQ (Q14) or pathogenic length polyQ (Q79) derived from carboxy-terminal fragments of the SCA3/MJD proteins under the control of tetracycline (Tet)-repressive promoter (Yasuda et al. 1999). Upon induction by Tet removal, Q79, but not Q14, formed polyQ aggregates (see below). IRE1 was detected as a doublet band without the induction of polyQ in both PC12-Q79 and PC12-Q14 cells (Fig. 1A, top, lanes 1,5$)$. On the other hand, induction of Q79, but not Q14, resulted in a shifted single band of IRE1 (Fig. 1A, lanes $3,4,7,8)$, which represents the autophosphorylated, and thus activated, form of IRE1 (Urano et al. 2000b). PERK was also activated by Q79, as determined by a similar band-shift analysis (Fig. 1A, bottom). Q79-specific induction of CHOP (another ER stress marker protein, also termed GADD153) was also observed (Fig. 1B, lanes 3,4). Thapsigargin, which triggers ER stress by depletion of lumenal calcium stores, induced IRE1/ PERK activations (Fig. 1A, lanes 2,6) and CHOP (Fig. 1B, lanes 2,6) in both PC12-Q79 and PC12-Q14 cells. This indicates that the Q79-specific activation of ER stress markers was not due to the clonal differences between PC12-Q79 and PC12-Q14 cells. To confirm these results in the more physiological conditions, we assessed the effect of polyQ on primary neurons derived from E14.5 mice. Adenovirus-mediated expression of Q79 (Ad-Q79), but not control $\beta$-galactosidase (Ad- $\beta$-gal) or Q35 (AdQ35; another SCA3/MJD-derived polyQ fragments within nonpathogenic repeat length; Ikeda et al. 1996) activated IRE1 and PERK (Fig. 1C, lanes 1-4) and induced the mRNAs of BiP (another ER stress marker; also known as GRP78) and CHOP (Fig. 1D, lanes 1-4) in neurons. These results indicate that polyQ aggregation causes ER stress in neuronal cells.

\section{Proteasomal dysfunction involved in polyQ-induced ER stress}

ER stress is induced by the accumulation of unfolded proteins within the ER lumen (Kaufman 1999; Urano et al. 2000a). Because polyQ peptide itself has neither a signal sequence nor transmembrane segment, it is unlikely that polyQ directly triggers ER stress within the ER. On the other hand, polyQ has been suggested recently to impair proteasomal activity in neuronal and non-neuronal cell lines (Bence et al. 2001; Jana et al. 2001; Orr 2001; Sherman and Goldberg 2001; Waelter et al. 2001). In addition, proteasome inhibition has been reported to induce ER chaperones in non-neuronal cells (Bush et al. 1997). Because misfolded proteins in the secretory pathway are normally exported from the ER back into the cytosol, where they are rapidly degraded by UPS (Johnson and Haigh 2000), disturbance of UPS by polyQ may lead to accumulation of unfolded proteins within the ER and, thus, to induce ER stress. We therefore examined whether alteration of proteasome activity was involved in the polyQ-induced ER stress. Ad-Q79, but not control Ad- $\beta$-gal or Ad-Q35 (data not shown) significantly inhibited the proteasome activity in mouse pri- 
A

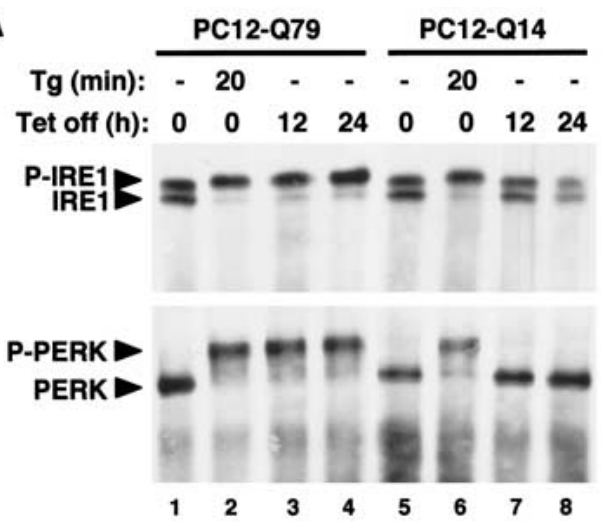

B

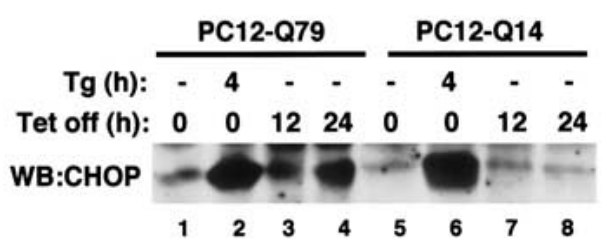

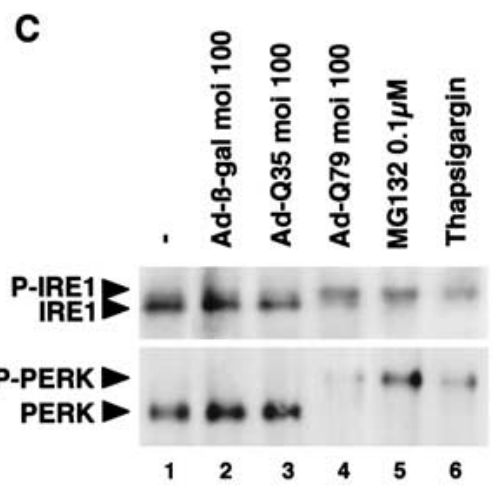

D

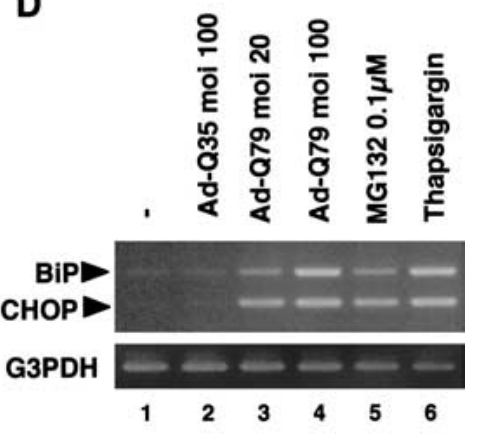

$\mathbf{E}$

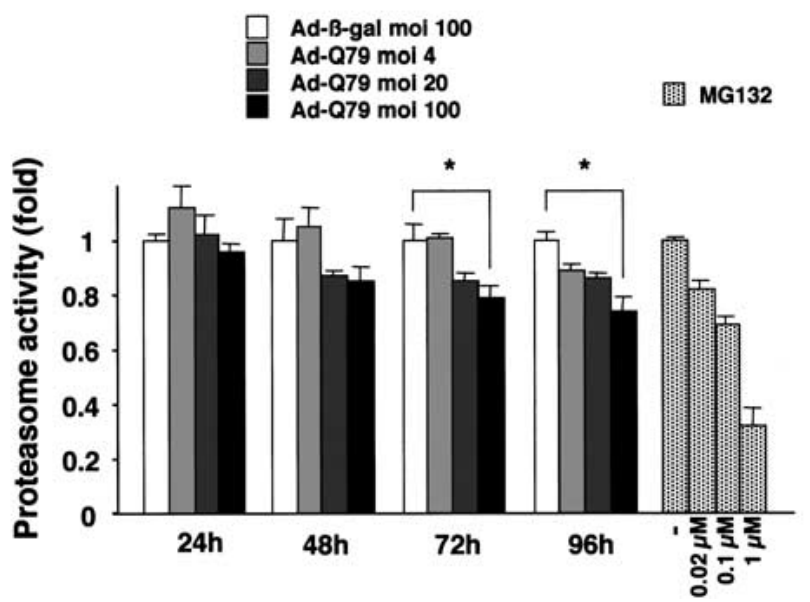

Figure 1. Expanded polyQ triggers ER stress through proteasomal dysfunction. (A) Activation of endogenous IRE1 and PERK by Q79. PC12-Q79 and PC12-Q14 cells $\left(5 \times 10^{6}\right.$ each) were lysed at each time point after treatment with $2 \mu M$ thapsigargin (Tg) or removal of Tet, and analyzed by immunoprecipitation (IP)-immunoblotting (WB) with anti-IRE1 $\alpha$ and anti-PERK antisera. (P-IRE1) Autophosphorylated IRE1; (P-PERK) autophosphorylated PERK. (B) Induction of CHOP by Q79. PC12-Q79, and PC12-Q14 cells (1 × $10^{6}$ each) were lysed with RIPA buffer at each time point after treatment with $2 \mu \mathrm{M}$ thapsigargin (Tg) or removal of Tet, and analyzed by WB with anti-CHOP antiserum. $(C)$ Activation of IRE1 and PERK by Q79 and proteasome inhibitor in primary neurons. Primary neurons $\left(1 \times 10^{6}\right)$ derived from day 14.5 mouse embryos were infected with the indicated m.o.i. of Ad- $\beta$-gal, Ad-Q35, or Ad-Q79 for 48 h, or treated with $0.1 \mu \mathrm{M}$ MG132 for $48 \mathrm{~h}$ or with $2 \mu \mathrm{M}$ thapsigargin for $1 \mathrm{~h}$. Cell lysates were analyzed by IP-WB with anti-IRE1 $\alpha$ and anti-PERK antisera. $(D)$ Induction of BiP and CHOP mRNA by Q79 and proteasome inhibitor in primary neurons. Results of RT-PCR following infection with the indicated m.o.i. of Ad-Q35 and Ad-Q79 for $48 \mathrm{~h}$ or treatments with MG132 (0.1 $\mu \mathrm{M}$ for $48 \mathrm{~h})$ and thapsigargin $(2 \mu \mathrm{M}$ for $1 \mathrm{~h})$. Expression of G3PDH was examined as a quantity control (bottom). (E) Inhibition of proteasomal activity by Q79. Primary neurons were infected with the indicated m.o.i. of Ad- $\beta$-gal or Ad-Q79 for the indicated time periods, or treated with the indicated concentration of MG132 for $1 \mathrm{~h}$. The proteasomal activity was measured as described in Materials and Methods and is shown as fold increase relative to that of Ad- $\beta$-gal-infected (for Ad-Q79) or untreated (for MG132) cells. Data are means ( \pm SE) of three independent experiments derived from independent embryos. $\left({ }^{\star}\right) P<0.05$ relative to control; significance calculated by Student's $t$-test.

mary neurons (Fig. 1E). Considering the infection efficiency of Ad-Q79 in MAP2-positive primary neurons ( 70\% at m.o.i. 100; data not shown), the inhibitory effect of Ad-Q79 at m.o.i. 100 after $96 \mathrm{~h}$ appeared to be comparable with that of $0.1 \mu \mathrm{M}$ or more of MG132 (a proteasome inhibitor) (Fig. 1E). Although the exact target of polyQ in the UPS remains unknown from these experiments, these results suggest that pathogenic polyQ impairs the function of UPS as has been suggested by use of different systems (Bence et al. 2001; Jana et al. 2001; Orr 2001; Sherman and Goldberg 2001; Waelter et al. 2001). To examine whether inhibition of proteasome activity may cause ER stress, the effects of proteasome inhibitor on the ER were assessed. When neurons were incubated with $0.1 \mu \mathrm{M} \mathrm{MG132}$ for $48 \mathrm{~h}$, the activations of IRE1 and PERK (Fig. 1C, lane 5) as well as the inductions of BiP and CHOP (Fig. 1D, lane 5) were clearly induced. These results suggest that polyQ triggers ER stress at least in part through proteasomal dysfunction.

ER stress activates ASK1 through IRE1-TRAF2-ASK1 complex formation

ER stress-activated IRE1 was shown recently to recruit TRAF2 on ER membrane and, thus, to activate JNK (Urano et al. 2000b); however, the molecular link be- 
tween the IRE1-TRAF2 complex and the JNK in ER stress signaling is missing. Because ASK1 interacts with TRAF2 upon TNF treatment and constitutes a TRAF2ASK1-SEK1/MKK4-JNK cascade in the TNF-signaling pathway (Nishitoh et al. 1998), we investigated whether ASK1 was also involved in ER stress signaling. We first examined the effect of ER stressors on the catalytic activity of ASK1 by using an antiphospho-ASK1 antibody that monitors activating phosphorylation of ASK1 (To- biume et al. 2002). Treatment of PC12 cells with thapsigargin or tunicamycin (an inhibitor of N-glycosylation in ER) activated endogenous ASK1 as well as JNK (Fig. 2A), indicating that ER stress activates the ASK1-JNK pathway.

Next, we examined the association of endogenous ASK1 and TRAF2 in untransfected PC12 cells. AntiASK1 antiserum specifically immunoprecipitated and detected the endogenous ASK1 protein as a major dou-
A

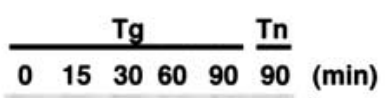

WB:P-ASK1 $L E E$ EE

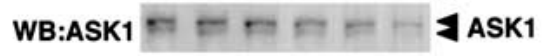
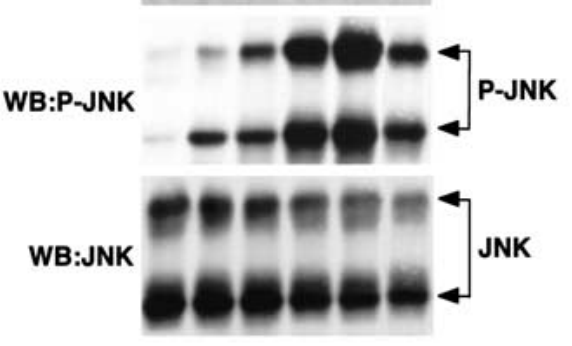

C

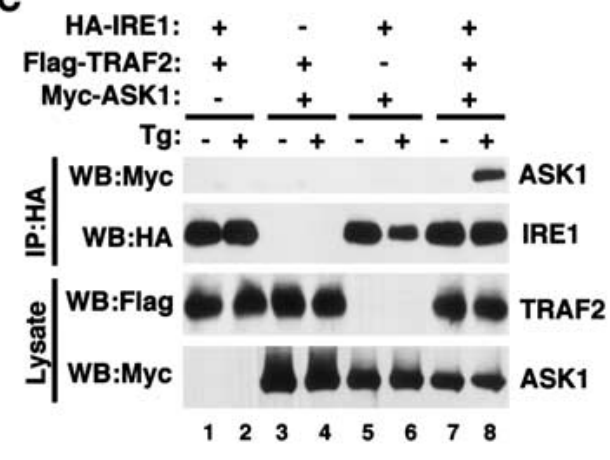

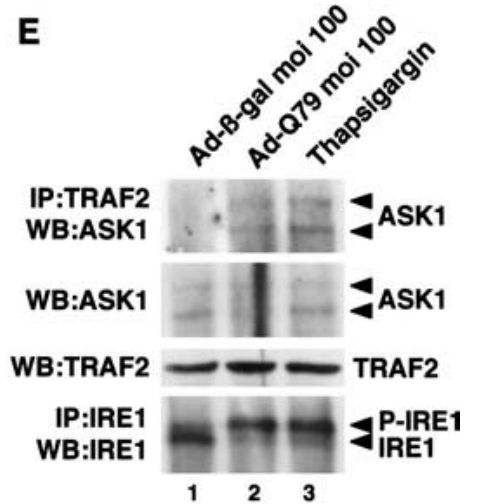

D

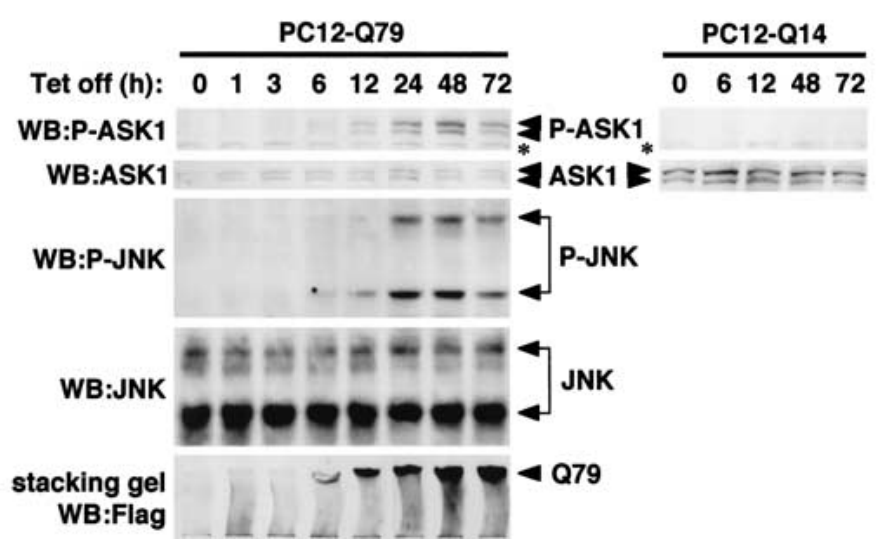

Figure 2. Expanded polyQ activates the IRE1-TRAF2-ASK1-JNK pathway. (A) ER stress-induced activation of ASK1-JNK pathway. PC12 cells $\left(1 \times 10^{6}\right)$ were treated with $20 \mu \mathrm{M}$ thapsigargin $(\mathrm{Tg})$ or $10 \mu \mathrm{g} / \mathrm{mL}$ tunicamycin $(\mathrm{Tn})$ for the indicated time periods. Cells were then lysed and immunoblotted with antibodies to phospho-ASK1 (P-ASK1) and phospho-JNK (P-JNK). Membranes were reprobed with antibodies to ASK1 and JNK as loading controls. The asterisk in the phospho-ASK1 panel denotes a nonspecific band detected. (B) ER stress-dependent endogenous interaction between ASK1 and TRAF2 in PC12 cells. Cell lysates from PC12 cells treated with $20 \mu M$ thapsigargin or $10 \mu \mathrm{g} / \mathrm{mL}$ tunicamycin for the indicated time periods were immunoprecipitated with anti-TRAF2 (IP: TRAF2), antiASK1 (IP: ASK1), or nonimmune antiserum (IP: Cont.). Coimmunoprecipitated ASK1 with TRAF2 was detected by immunoblotting with anti-ASK1. Presence of ASK1 and TRAF2 was confirmed by immunoblotting using the same lysates. $(C)$ ER stress-induced IRE1-TRAF2-ASK1 complex in transfected 293 cells. The 293 cells were transiently transfected with pcDNA3-HA-IRE1 (1.2 $\mu \mathrm{g})$, pcDNA3-Flag-TRAF2 $(0.3 \mu \mathrm{g})$ and pcDNA3-myc-ASK1 $(0.5 \mu \mathrm{g})$ in the indicated combinations. After $12 \mathrm{~h}$, cells were treated with 20 $\mu \mathrm{M}$ thapsigargin for $20 \mathrm{~min}$, immunoprecipitated with anti-HA (12CA5), and immunoblotted (WB) with anti-myc (9E10) and anti-HA (3F10) antibodies. The appropriate expressions of Flag-TRAF2 and Myc-ASK1 were confirmed in the same lysates. $(D)$ Activation of ASK1-JNK pathway by pathogenic polyQ. PC12-Q79 and PC12-Q14 cells were lysed at each time point after removal of Tet and analyzed by immunoblotting with antibodies to phospho-ASK1 (P-ASK1) and phospho-JNK (P-JNK). Membranes were reprobed with antibodies to ASK1 or JNK as loading controls. The asterisk in the phospho-ASK1 panel denotes a nonspecific band. Expression of Flag-Q79 was verified by immunoblotting with anti-Flag antibody. Immunoreactive bands of Q79 were detected at the top of the stacking gel accompanied by a smearing pattern (bottom). (E) PolyQ-dependent endogenous interaction between ASK1 and TRAF2 in primary neurons. Cell lysates from primary neurons $\left(1 \times 10^{7}\right)$, infected with Ad- $\beta$-gal or Ad-Q79 at m.o.i. 100 for $48 \mathrm{~h}$, or treated with $20 \mu \mathrm{M}$ thapsigargin for $20 \mathrm{~min}$, were immunoprecipitated with anti-TRAF2 (IP: TRAF2). Coimmunoprecipitated ASK1 with TRAF2 was detected by immunoblotting with anti-ASK1. Activation of IRE1 was confirmed by IP-WB with anti-IRE1 $\alpha$ antiserum using the same lysates (bottom). (P-IRE1) Autophosphorylated IRE1. 
blet of bands (Fig. 2B, lane 2). When lysates from thapsigargin- or tunicamycin-treated cells were immunoprecipitated with anti-TRAF2 antiserum and immunoblotted with anti-ASK1 antiserum, ASK1 was found to associate with TRAF2 in an ER stress-dependent manner (Fig. 2B, lanes 5-7). This interaction was observed within $15 \mathrm{~min}$ and continued until $60 \mathrm{~min}$ after treatment with thapsigargin, which correlates well with the time course of thapsigargin-induced activation of ASK1 and JNK (Fig. 2A). Activation of IRE1 and complex formation of endogenous TRAF2 and ASK1 were also observed in thapsigargin-treated primary neurons (Fig. 2E, lane 3). These results suggest that ER stress activates the ASK1-JNK pathway through induction of the TRAF2-ASK1 complex. To investigate whether IRE1 recruits TRAF2 and ASK1 in an ER stress-dependent manner, Myc-ASK1, HA-IRE1, and Flag-TRAF2 were transfected into 293 cells and subjected to coimmunoprecipitation analysis (Fig. 2C). ASK1 was found to associate with IRE1 only in the presence of TRAF2 plus thapsigargin (Fig. 2C, top, lane 8), suggesting that ER stress induces formation of an IRE1-TRAF2-ASK1 complex on the ER outer membrane and thus activates the ASK1-JNK pathway.

\section{Expanded polyQ activates ASK1 through ER stress}

We next examined whether polyQ with pathogenic repeat length activates ASK1. Induction of Q79, but not Q14, activated endogenous ASK1 in PC12 cells after $6 \mathrm{~h}$ of Tet removal (Fig. 2D, top, for PC12-Q79). JNK was activated in parallel with this. The onset of polyQ aggregation (Fig. 2D, bottom, for PC12-Q79; aggregates can be detected by immunoblotting of stacking gel) coincided with the activation of ASK1 and JNK. To confirm that the polyQ-induced activation of ASK1 was mediated by the polyQ-induced ER stress, we examined whether polyQ induces the interaction between endogenous ASK1 and TRAF2 in mouse primary neurons. ASK1 was found to associate with TRAF2 in the cells infected with Ad-Q79 but not Ad- $\beta$-gal (Fig. 2E, top, lanes 1,2). Taken together, these findings indicate that pathogenic polyQ activated the ASK1-JNK pathway by triggering ER stress.

ASK1 is required for ER stress-and proteasomal dysfunction-induced INK activation

ASK1 is required for TNF- and oxidative stress-induced activation of JNK and apoptosis (Ichijo et al. 1997; Saitoh et al. 1998; Tobiume et al. 2001). We assessed the requirement of ASK1 for ER stress- and proteasomal dysfunction-induced JNK activation by using MEFs and primary neurons derived from $A S K 1^{-/-}$mice. Activation of endogenous JNK by thapsigargin and MG132 was almost completely eliminated in $A S K 1^{-/-}$MEFs (Fig. 3A,B) and $A S K 1^{-1-}$ primary neurons (Fig. 4D, lanes 2,3,8,9). Overexpression of IRE1 activated the cotransfected JNK in ASK $1^{+/+}$MEFs but not at all in $A S K 1^{-/-}$MEFs (Fig. 3C). Reintroduction of ASK1 in $A S K 1^{-/-}$MEFs restored JNK activation (Fig. 3D, lanes 5,10), suggesting that downstream components of ASK1 are intact in $A S K 1^{-/-}$MEFs. TRAF2-induced maximal activation of JNK in $A S K 1^{+/+}$ MEFs (2.9-fold) was reduced (1.3-fold) but not completely lost in $A S K 1^{-1-}$ MEFs (Fig. 3D, lanes 2-4,7-9). This residual JNK activation by TRAF2 in $A S K^{-/-}$MEFs may occur via a redundant pathway involving GCK/GCKRMEKK1, which operates in TRAF2-mediated TNF signaling (Yuasa et al. 1998). Consistently, TNF-induced JNK activation was partially, but not completely, lost in ASK1 ${ }^{-/-}$MEFs (Tobiume et al. 2001). These results rather demonstrate a nonredundant and highly specific role of ASK1 in ER stress-induced JNK activation.

\section{ASK1 is required for ER stress- and proteasomal dysfunction-induced cell death}

We next examined whether ASK1 is required for ER stress- and proteasomal dysfunction-induced cell death. Apoptotic cell death was clearly induced by thapsigargin in $A S K 1^{+/+}$MEFs, as determined by cell morphology (Fig. $3 \mathrm{E}$, panels a,c,e,g) and terminal deoxynucleotidyl transferase-mediated dUTP nick-end labeling (TUNEL) staining (Tobiume et al. 2001) (Fig. 3E, panels b,d,f,h). Within $6 \mathrm{~h}$ after treatment with thapsigargin, nearly $100 \%$ of $A S K 1^{+/+}$MEFs became TUNEL positive (Fig. $3 \mathrm{~F}$ ); in contrast, $A S K 1^{-/-}$MEFs were almost completely resistant to thapsigargin-induced apoptosis (Fig. 3E,F). ASK1 ${ }^{-/-} \mathrm{MEFs}$ were also resistant to other ER stressors including tunicamycin and dithiothreitol, as determined by 3 '-(4,5-dimethyl-2-thiazolyl)-2,5-diphenyl-2H-tetrazolium bromide (MTT) assay (data not shown). Proteasomal dysfunction has been reported to induce apoptosis in various cell types including neuronal cells (Sadoul et al. 1996; Drexler 1997; Qiu et al. 2000). We examined whether ASK1 is required for apoptosis induced by the proteasome inhibitors. ASK $1^{-/-}$and $A S K 1^{+/+}$MEFs were incubated with various proteasome inhibitors, including MG132, Lactacystin, and Proteasome inhibitor I; apoptotic cell death was analyzed by TUNEL assay. Proteasome inhibitor-induced apoptosis in $A S K 1^{-/-}$MEFs were significantly lower than that in $A S K 1^{+/+}$MEFs (Fig. 3G). The requirement of ASK1 for ER stress- and proteasomal dysfunction-induced cell death was also shown in the primary neurons as determined by an MTT assay (Fig. 4A-C). These results indicate that ASK1 is an essential component of the ER stress- and proteasomal dysfunction-induced cell death.

\section{ASK1 is required for polyQ-induced neuronal cell death}

Next, we examined the requirement of ASK1 for polyQinduced JNK activation and neuronal cell death. Because JNK3 is selectively expressed in the brain and implicated in excitotoxicity-induced neuronal cell death (Yang et al. 1997), we determined the JNK3 activity in $A S K 1^{+/+}$and $A S K 1^{-/-}$primary neurons. Ad-Q79 activated JNK3 in $A S K 1^{+/+}$primary neurons in an m.o.i.-dependent man- 


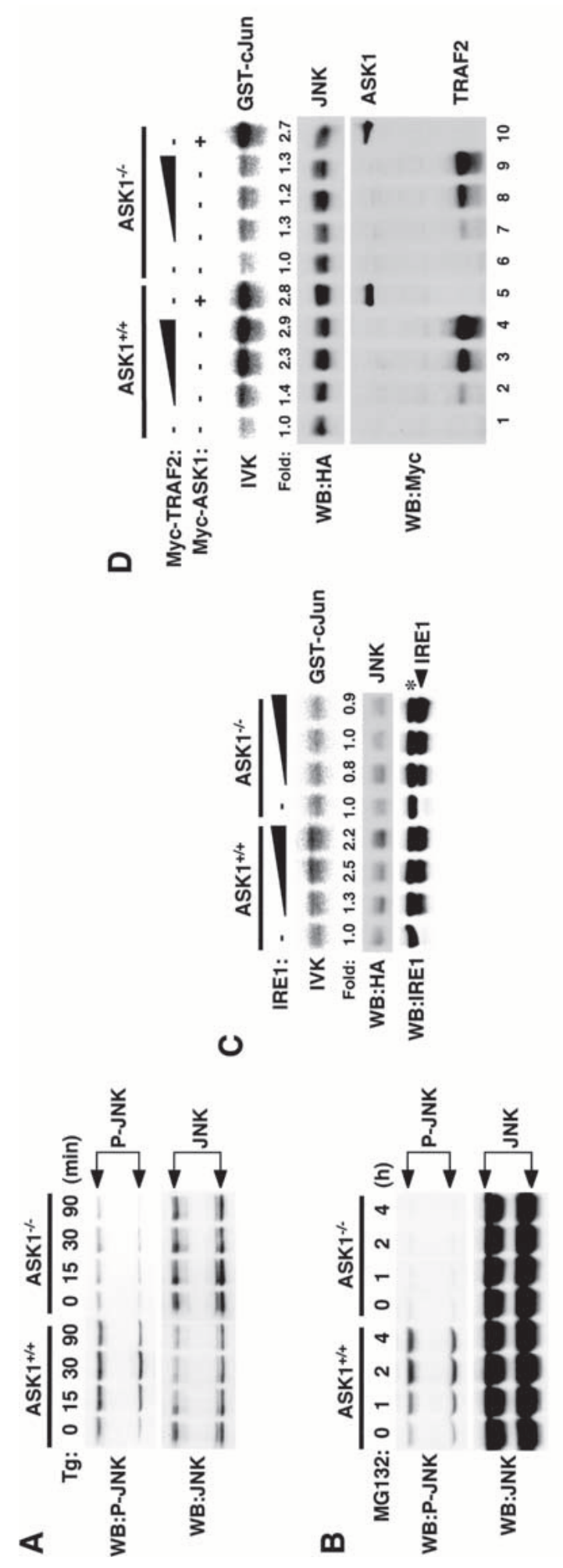

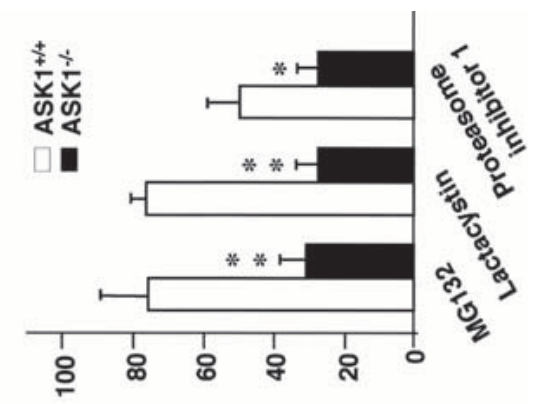

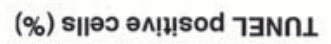

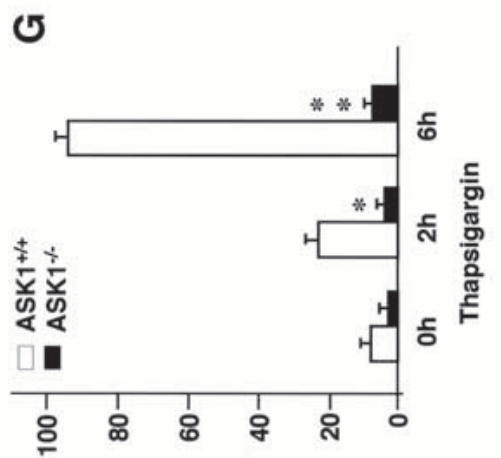

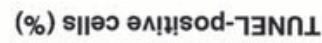

L.
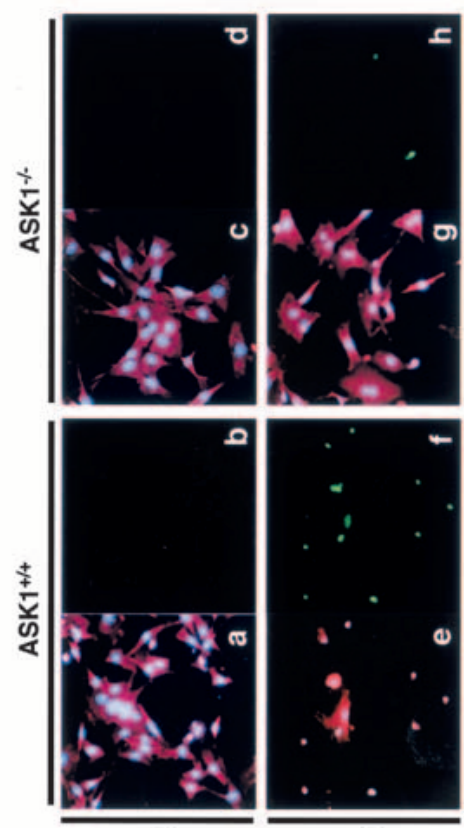

U

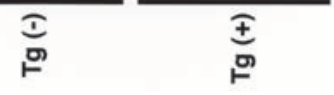

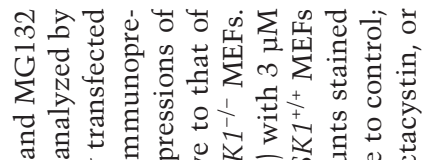

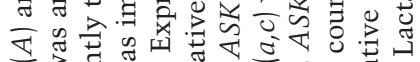

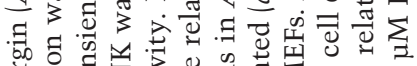
ज.

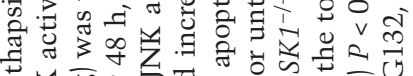

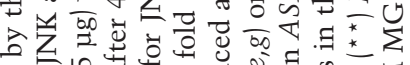

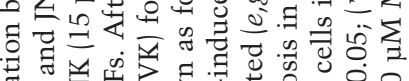

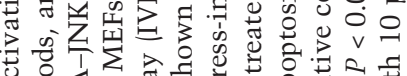

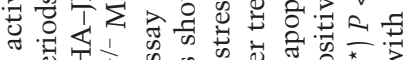

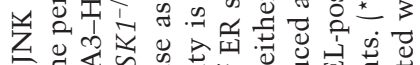

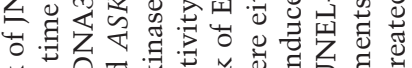

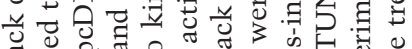

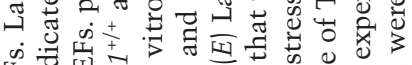

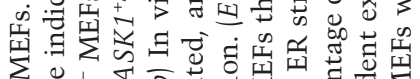

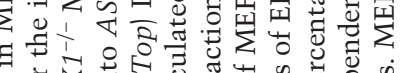

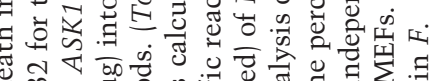
ปூ

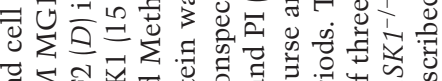

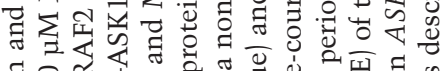

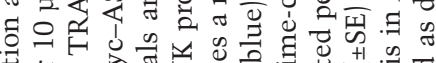

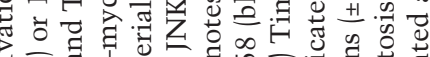

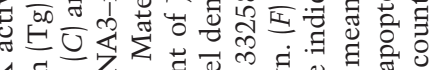

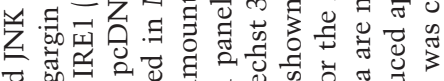

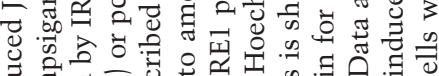

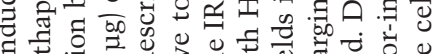

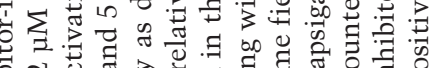

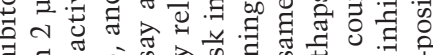

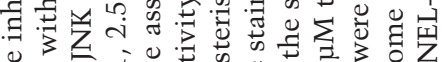

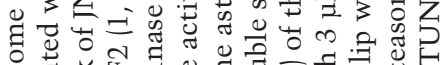

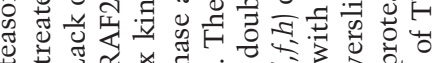

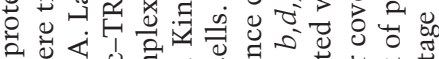
उ

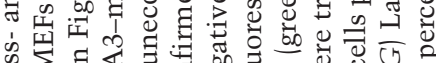

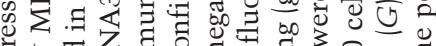

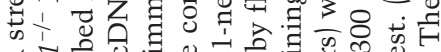

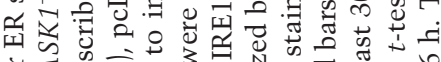

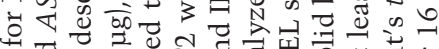

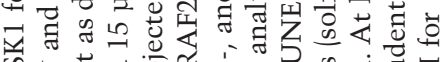

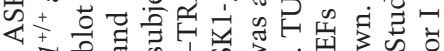
पै $\begin{gathered}0 \\ 0\end{gathered}$

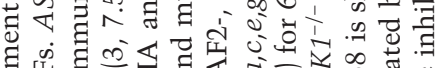

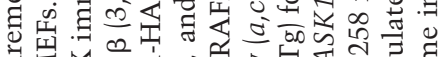

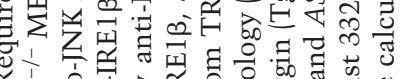
4 का क्षे की चु

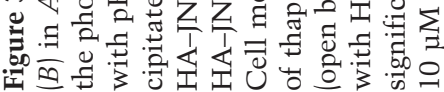


A

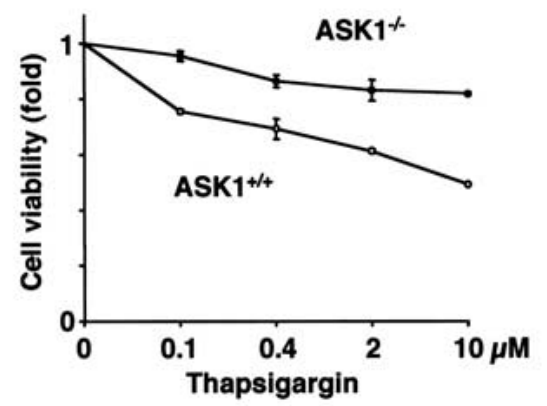

B

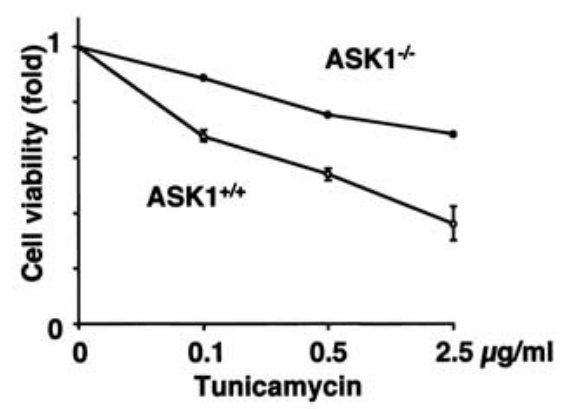

C

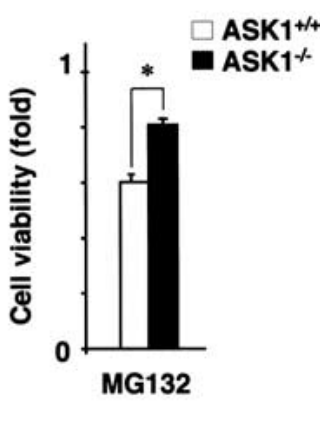

D

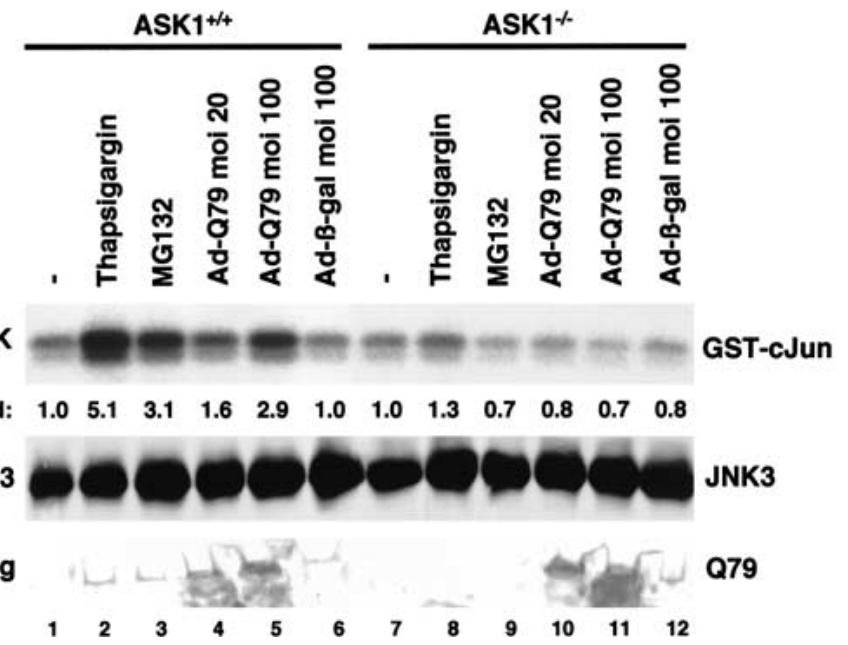

$\mathbf{E}$

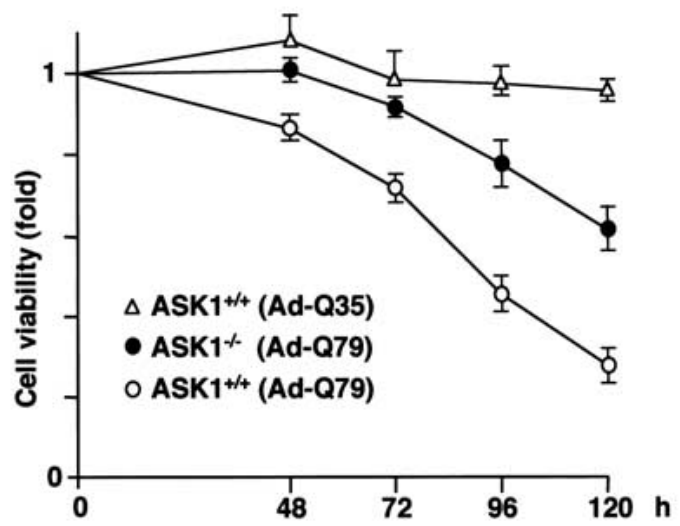

Figure 4. Requirement of ASK1 for ER stress-, proteasome inhibitor-, and polyQ-induced JNK activation and cell death in neurons. $(A, B)$ Lack of ER stress-induced cell death in $A S K 1^{-/-}$primary neurons. $A S K 1^{+/+}$neurons $(O)$ and $A S K 1^{-/-}$neurons $(\bullet)$ were treated with the indicated concentration of thapsigargin or tunicamycin for $16 \mathrm{~h}$. The graphs show the cell viability determined by MTT assay as described in Materials and Methods. (C) Reduction of proteasome inhibitor-induced cell death in $A S K 1^{-/-}$primary neurons. ASK1 ${ }^{+/+}$ neurons (open bar) and $A S K 1^{-/-}$neurons (solid bar) were treated with $0.1 \mu \mathrm{M} \mathrm{MG132}$ for $16 \mathrm{~h}$. The graph shows the cell viability determined by MTT assay. Data are means $( \pm \mathrm{SE})$ of three independent experiments derived from independent embryos $(A-C)$. $\left({ }^{\star}\right)$ $P<0.05$ relative to control; significance calculated by Student's $t$-test. $(D)$ Lack of polyQ-, proteasome inhibitor-, and ER stress-induced JNK activation in $A S K 1^{-/-}$primary neurons. $A S K 1^{+/+}$neurons and $A S K 1^{-/-}$neurons were infected with the indicated m.o.i. of Ad- $\beta$-gal or Ad-Q79 for $48 \mathrm{~h}$, or treated with $2 \mu \mathrm{M}$ thapsigargin for $30 \mathrm{~min}$, or $10 \mu \mathrm{M}$ MG132 for $2 \mathrm{~h}$. JNK3 was immunoprecipitated by anti-JNK3 monoclonal antibody and subjected to immunecomplex kinase assay as described in Materials and Methods. (Top) IVK for JNK3 activity. Expressions of JNK3 (middle) and Flag-Q79 (bottom) in the same lysate are shown. Kinase activity relative to the amount of JNK3 protein was calculated, and activity is shown as fold increase relative to that of JNK3 from unstimulated cells. $(E)$ Time-course analysis of polyQ-induced cell death in $A S K 1^{+/+}$and $A S K 1^{-/-}$primary neurons. $A S K 1^{+/+}$neurons $(O, \triangle)$ and $A S K 1^{-/-}$neurons $(\bullet)$ were infected with Ad-Q79 or Ad-Q35 at m.o.i. 100 for the indicated time periods. The graph shows the cell viability determined by MTT assay as described in Materials and Methods. Data are means $( \pm \mathrm{SE})$ of 10 independent experiments derived from independent embryos.

ner, whereas no increase in JNK3 activity was observed in ASK1 $^{-/-}$neurons (Fig. 4D, lanes 4,5,10,11). Neither Ad- $\beta$-gal nor Ad-Q35 activated JNK3 (Fig. 4D, lane 6; data not shown) in $A S K 1^{+/+}$primary neurons. ASK1 $1^{-/-}$ neurons were also insensitive to thapsigargin and MG132 in JNK3 activation (Fig. 4D, lanes 2,3,8,9). These results indicate that ASK1 is required for JNK3 activation by pathogenic polyQ. PolyQ-induced cell death was determined by MTT assay (Fig. 4E). Q79, but not Q35, induced cell death in $A S K 1^{+/+}$neurons. ASK1 $1^{-/-}$neurons were clearly more resistant to Q79-induced cell death than $\mathrm{ASK}^{+/+}$neurons (Fig. 4E), indicating that ASK1 is required for polyQ-induced neuronal cell death.

\section{Discussion}

We have identified ASK1 as an essential component in the neuronal death signaling induced by expanded polyQ. Expanded polyQ has been known to cause various cellular events, including alteration of gene expression, abnormal protein interaction, and activation of caspase (Lin et al. 1999; Paulson et al. 2000), and all of these abnormal alterations potentially trigger neuronal cell death (Fig. 5). However, direct genetic evidence has never been provided to the hypothetical involvement of these events in the polyQ-induced cell death pathway. In the present study, we have shown that polyQ induces ER 
Nishitoh et al.

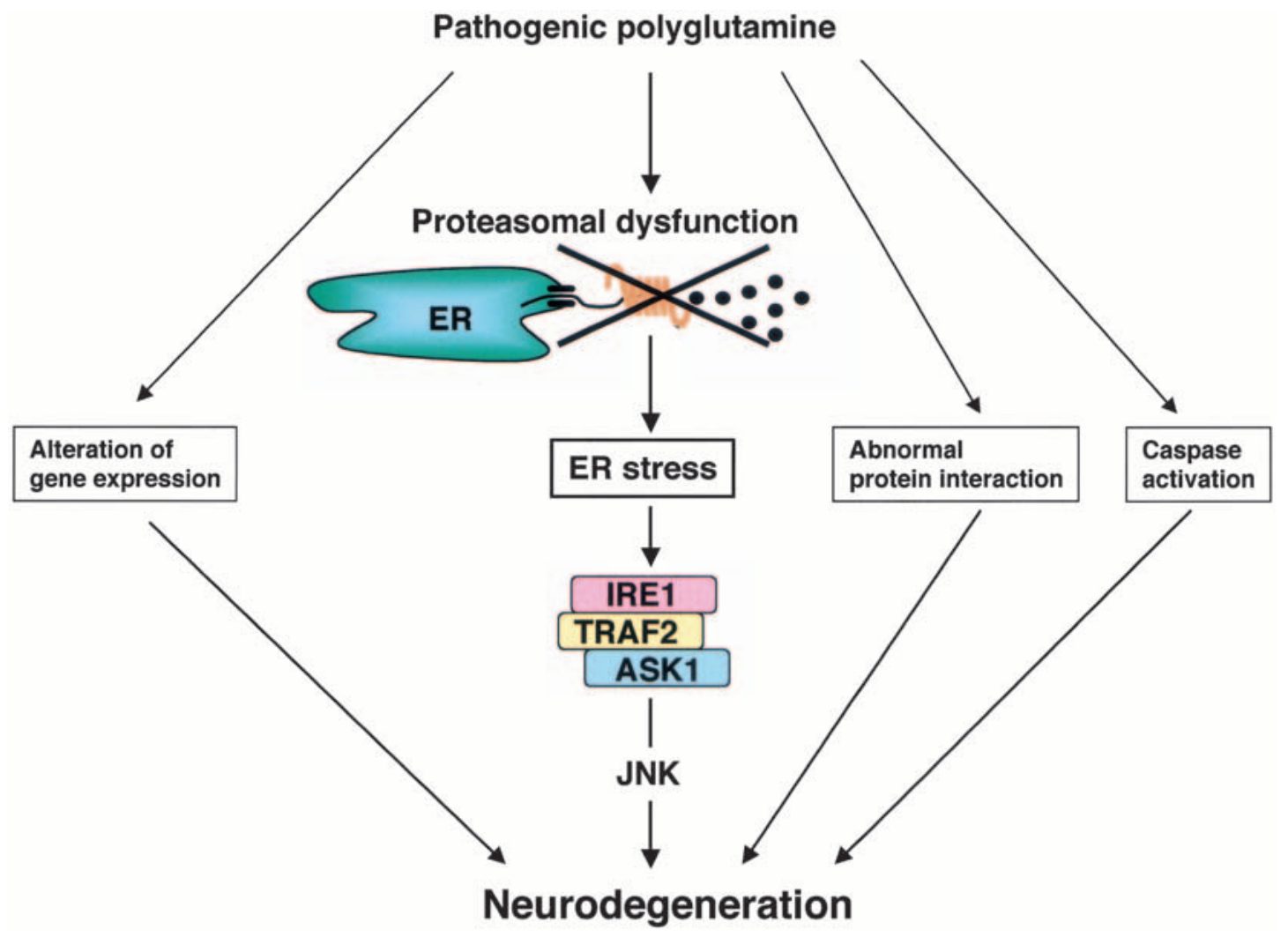

Figure 5. Schematic representation of the role of IRE1-TRAF2-ASK1 cascade in the pathogenesis of polyQ disease. See text for details.

stress, which in turn activates the IRE1-TRAF2-ASK1JNK-signaling pathway leading to neuronal cell death (Fig. 5). The almost complete loss of JNK activation (Figs. 3A, 4D) and cell death (Figs. 3E,F, 4A,B) induced by ER stressors in $A S K 1^{-/-}$cells strongly argues that ASK1 constitutes an essential and nonredundant cell death pathway in response to ER stress.

Recent studies have suggested that polyQ disturbs UPS (Bence et al. 2001; Jana et al. 2001; Waelter et al. 2001), and thus compromise its ability to degrade not only polyQ but also unfolded proteins produced at a normal protein turnover. UPS dysfunction has been implicated in the pathogenesis of various neurodegenerative diseases (Sherman and Goldberg 2001) such as amyotrophic lateral sclerosis (Johnston et al. 2000) and Parkinson's disease (Imai et al. 2001). However, the molecular mechanism by which polyQ-induced UPS dysfunction leads to neuronal cell death has remained unknown. Although polyQ-induced inhibition of the proteasome activity in primary neurons were incomplete $1 \sim 30 \%$ at most by Ad-Q79 at m.o.i. of 100; Fig. 1E), such an extent of proteasome dysfunction was sufficient to cause ER stress (Fig. 1C,D) and neuronal cell death (Fig. 4C). These results suggested that polyQ-induced proteasomal dysfunction and neuronal cell death can be linked by the ER stress-dependent cell death pathway. Consistently, activations of JNK by polyQ or proteasome inhibitors were completely abrogated in $A S K 1^{-/-}$cells (Figs. 3B, 4D), and
$A S K 1^{-/-}$cells were refractory to polyQ- and proteasome inhibitor-induced apoptosis (Figs. 3G, 4C,E). This indicates that ASK1 is a key component in the polyQ-initiated cell death signaling cascade involving UPS dysfunction and ER stress (Fig. 5). On the other hand, resistance to proteasome inhibitor-induced apoptosis in $A S K 1^{-/-}$ cells was not as dramatic as that to ER stress-induced apoptosis (Figs. 3G, 4C). These results suggest that ASK1-JNK- and ER stress-independent cell death pathway may also exist in the downstream of proteasome dysfunction. This may also reflect, in part, the incomplete resistance of $A S K 1^{-/-}$neurons to polyQ-induced cell death (Fig. 4E).

It has been suggested that neuronal cell death may not be necessary for the trigger of atrophy and ataxia. This hypothesis is supported by a recent study that showed the reversal motor dysfunction in a conditional HD model mouse in which expression of polyQ proteins were regulated by tetracycline-repressor (Yamamoto et al. 2000). In this mouse model, expression of polyQ induced HD-like phenotype without a significant decrease in neuron number, and blockade of expression of polyQ leads to disappearance of aggregation and an amelioration of the behavioral phenotype. Thus, polyQ-induced neuronal cell death might not be a primary event required for the initiation of polyQ diseases phenotype. Nevertheless, considering the slow progressive nature of the human polyQ diseases accompanied by substantial 
loss of neurons, it is unlikely that polyQ diseases can eventually be cured without prevention of neuronal cell death. In this regard, whether ASK1 deficiency mitigates polyQ disease phenotype in appropriate mouse models will be an interesting issue to be examined.

Another important issue to be elucidated is the relation between the ASK1-JNK pathway and caspase12, which has been reported to be essential for ER stressinduced apoptosis and neurotoxicity by amyloid- $\beta$ proteins (Nakagawa et al. 2000). It is currently unclear whether the ASK1-JNK cascade is required for caspase 12 activation, or vice versa. However, whereas ASK1 is activated within $15 \mathrm{~min}$ in response to ER stress, caspase 12 activation occurs much slower after increase in production of inactive caspase12 precursor (Harding et al. 2000). ASK1 may thus lie upstream of caspase12. Alternatively, these two cascades might contribute independently to different neurodegenerative disorders (e.g., Alzheimer's disease and polyQ diseases).

Here, we propose a novel mechanism by which expanded polyQ repeats cause neuronal cell death through UPS dysfunction, ER stress, and the ASK1-JNK pathway. Exactly how pathogenic polyQ compromises UPS that is required for ER-associated degradation (ERAD) also remains to be elucidated. However, recent findings that a complex of Cdc48/p97/VCP (an AAA ATPase family member), Udf1 (a protein involved in the degradation of ubiquitin fusion proteins at post-ubiquitination steps), and Npl4 is required for the extraction of proteins from the ER to cytosol (Ye et al. 2001), and that Cdc48/p97/ VCP interacts and colocalizes with expanded polyQ (Hirabayashi et al. 2001), suggest that polyQ might thus target an ERAD-specific UPS involving the Cdc48/p97/ VCP-Udf1-Npl4 complex. Because dysfunctions of UPS and the ER appear to be involved in the pathogenesis of many neurodegenerative diseases, ASK1 may be a potential therapeutic target for various neurodegenerative disorders represented by polyQ diseases.

\section{Materials and methods}

\section{Cells and cell cultures}

PC12 cells, PC12-Q79 and PC12-Q14, were maintained as described (Yasuda et al. 1999). ASK1 ${ }^{-/-}$and $A S K 1^{+/+}$MEFs were obtained from E12.5 embryos (Tobiume et al. 2001). For primary neurons, telencephalons from E14.5 mice were triturated in HBSS by mild and frequent pipetting. Dissociated cells were cultured in N2-supplemented DMEM-F12 medium on assay plates precoated with poly-L-ornithine and fibronectin.

\section{Expression plasmid and transfection}

pBabe-IRE1 $\beta$ was obtained from D. Ron (Urano et al. 2000b). pcDNA3-Flag-TRAF2 (Nishitoh et al. 1998), pcDNA3-HAASK1 (Saitoh et al. 1998), and pcDNA3-HA-JNK (Nishitoh et al. 1998) have been described. HA-IRE1 $\beta$, Myc-TRAF2, and Myc-ASK1 were constructed in pcDNA3 (Invitrogen) by PCR. Transfection was performed with FuGENE6 (Roche) according to the manufacturer's instructions.

\section{Antibodies}

Rabbit polyclonal antiserum to phospho-ASK1 was directed against a phosphorylated peptide fragment of mouse ASK1 (the peptide sequence $\mathrm{C}^{842}$ TETFTGTLQY ${ }^{852}$ containing phosphorylated Thr 845 that is essential for ASK1 activation; Tobiume et al. 2002). Specific antibody was affinity purified by use of phosphorylated and nonphosphorylated peptide columns. Antiserum to ASK1 (DAV) has been described (Nishitoh et al. 1998). Antisera to IRE1 $\alpha$, IRE1 $\beta$, PERK, and CHOP were obtained from D. Ron.

\section{Infection of recombinant adenoviruses}

Recombinant adenoviruses encoding Flag-Q79 and $\beta$-galactosidase were constructed as described (Saitoh et al. 1998). Primary neurons were cultured in N2-supplemented DMEM-F12 medium for $6 \mathrm{~h}$ and infected with recombinant adenoviruses. About $70 \%$ of primary neurons can be successfully infected at a multiplicity of infection (m.o.i.) of 100 as determined by immunocytochemistry with antibodies to MAP2 (Sigma) and Flag (M2) (data not shown).

\section{Proteasomal assay}

Approximately $6 \times 10^{5}$ primary neurons were lysed in the CHAPS buffer containing $50 \mathrm{mM}$ Tris- $\mathrm{HCl}$ (pH 7.5), $100 \mathrm{mM}$ $\mathrm{NaCl}, 0.2 \%$ CHAPS, $5 \mathrm{mM}$ EDTA, 1 mM EGTA, $3 \mathrm{mM} \mathrm{NaN}_{3}$, and protease inhibitor cocktail (Sigma) after infection with recombinant adenoviruses or stimulation with MG132 (Calbiochem), and cell extracts were clarified by centrifugation. For measurement of the chymotrypsin-like peptidase activity of the proteasome, Succinil-Leu-Leu-Val-Tyr-7 amino-4-methylcoumarin (Suc-LLVY-AMC; Bachem) was taken from a stock of 40 $\mathrm{mM}$ (DMSO) to yield a final concentration of $50 \mu \mathrm{M}$. Substrate were diluted in $50 \mathrm{mM}$ Tris- $\mathrm{HCl}$ (pH 7.3), $100 \mathrm{mM} \mathrm{NaCl}, 5 \mathrm{mM}$ EDTA, $1 \mathrm{mM}$ EGTA, $3 \mathrm{mM} \mathrm{NaN}_{3}$, and $2 \mathrm{mM}$ DTT. A total of $80 \mu \mathrm{L}$ of cell extract were incubated with $100 \mu \mathrm{L}$ of substrate solution for $15 \mathrm{~min}$ at $37^{\circ} \mathrm{C}$. Fluorescence of the released AMC was measured with an excitation wavelength of $380 \mathrm{~nm}$ and emission wavelength of $440 \mathrm{~nm}$ (CytoFluor2350; Millipore).

\section{$R T-P C R$}

Total RNA was isolated from $6 \times 10^{5}$ primary neurons using ISOGEN kit (Nippongene). RNA (10 $\mu$ g) was reverse transcribed with SuperScript II (Life Technologies) according to the manufacturer's instructions. The primers used for PCR were as follows. BiP, 5'-AAGGTCTATGAAGGTGAACGACCCC-3' and 5'-GACCCCAAGACATGTGAGCAACTGC-3'; CHOP, 5' -ACTACTCTTGACCCTGCGTCCCTAG-3' and 5'-CATGTGCAGTGCAGTGCAGGGTCAC-3'; and G3PDH (Clontech).

\section{Immunoblotting analysis}

Immunoblotting analysis has been described (Tobiume et al. 2001). Blots were probed with antibodies to JNK1 (Santa Cruz), phospho-JNK (Cell Signaling), ASK1, phospho-ASK, and CHOP.

\section{Band-shift analysis for IRE1 and PERK}

Approximately $5 \times 10^{6}$ PC12-Q79 and PC12-Q14 cells were washed with PBS and cultured in DMEM containing $1 \%$ HS without Tet. Cells were lysed in the lysis buffer as described (Nishitoh et al. 1998). Cell extracts were clarified by centrifugation, and the supernatants were immunoprecipitated with an- 
tisera to IRE $1 \alpha$ and PERK. Proteins were resolved by SDS-PAGE under reducing conditions and immunoblotted with antisera to IRE $1 \alpha$ and PERK.

\section{Coimmunoprecipitation analysis}

Coimmunoprecipitation analysis using transfected 293 cells has been described (Nishitoh et al. 1998). For endogenous coimmunoprecipitation analysis, $5 \times 10^{6}$ of nontransfected $\mathrm{PC} 12$ cells and $1 \times 10^{7}$ primary neurons were lysed in the lysis buffer after stimulation with thapsigargin or tunicamycin and infection with recombinant adenoviruses, respectively. Cell lysates were immunoprecipitated with antibodies to ASK1 or TRAF2 (Upstate Biotechnology). Proteins were resolved by SDS-PAGE and immunoblotted with antibody to ASK1.

\section{Immunecomplex kinase assay for JNK}

Approximately $1.5 \times 10^{7} \mathrm{MEFs}$ in 15 -cm diameter plates were transiently transfected with the expression vectors using $\mathrm{Fu}-$ GENE6. After $48 \mathrm{~h}$, cells were lysed with the lysis buffer and immunoprecipitated with anti-HA antibody (12CA5; Roche). For JNK3 kinase assay, $2 \times 10^{6}$ primary neurons were infected with recombinant adenoviruses. After $48 \mathrm{~h}$, cells were lysed with the lysis buffer and immunoprecipitated with anti-JNK3 antibody (Transduction Laboratories). The kinase assay using GST-cJun (1-79) has been described (Nishitoh et al. 1998). The amount of JNK protein was determined by immunoblotting with anti-HA antibody (3F10; Roche) or antibody to JNK1 (Santa Cruz), and quantified by densitometric analysis (Quantity One program; pdi).

\section{MTT assay}

Cell viability of primary neurons was determined as described (Tobiume et al. 2001). The relative number of surviving cells was determined in triplicate by estimating the value of unstimulated or uninfected cells as $100 \%$. Thus, onefold means that $100 \%$ of cells are viable as compared with control.

\section{Acknowledgments}

We thank D. Ron, F. Urano, and K. Kohno for providing plasmids and antibodies and for valuable comments; K. Nakashima and M. Yanagisawa for technical support; and H. Mizusawa and K. Ishikawa for discussion. We thank all of the members of Cell Signaling Laboratory for their critical comments. This work was supported by Grants-in-Aid for scientific research from the Ministry of Education, Culture, Sports, Science, and Technology of Japan; Uehara Memorial Foundation; The Cell Science Research Foundation; and Mitsubishi Foundation.

The publication costs of this article were defrayed in part by payment of page charges. This article must therefore be hereby marked "advertisement" in accordance with 18 USC section 1734 solely to indicate this fact.

\section{References}

Bence, N.F., Sampat, R.M., and Kopito, R.R. 2001. Impairment of the ubiquitin-proteasome system by protein aggregation. Science 292: 1552-1555.

Bertolotti, A., Zhang, Y., Hendershot, L.M., Harding, H.P., and Ron, D. 2000. Dynamic interaction of BiP and ER stress transducers in the unfolded-protein response. Nat. Cell Biol. 2: $326-332$
Bush, K.T., Goldberg, A.L., and Nigam, S.K. 1997. Proteasome inhibition leads to a heat-shock response, induction of endoplasmic reticulum chaperones, and thermotolerance. $I$. Biol. Chem. 272: 9086-9092.

Delepine, M., Nicolino, M., Barrett, T., Golamaully, M., Lathrop, G.M., and Julier, C. 2000. EIF2AK3, encoding translation initiation factor $2-\alpha$ kinase 3 , is mutated in patients with Wolcott-Rallison syndrome. Nat. Genet. 25: 406-409.

DiFiglia, M., Sapp, E., Chase, K.O., Davies, S.W., Bates, G.P., Vonsattel, J.P., and Aronin, N. 1997. Aggregation of huntingtin in neuronal intranuclear inclusions and dystrophic neurites in brain. Science 277: 1990-1993.

Drexler, H.C. 1997. Activation of the cell death program by inhibition of proteasome function. Proc. Natl. Acad. Sci. 94: 855-860.

Harding, H.P., Zhang, Y., Bertolotti, A., Zeng, H., and Ron, D. 2000. Perk is essential for translational regulation and cell survival during the unfolded protein response. Mol. Cell 5: 897-904.

Harding, H.P., Zeng, H., Zhang, Y., Jungries, R., Chung, P., Plesken, H., Sabatini, D.D., and Ron, D. 2001. Diabetes mellitus and exocrine pancreatic dysfunction in perk-/- mice reveals a role for translational control in secretory cell survival. Mol. Cell 7: 1153-1163.

Hatai, T., Matsuzawa, A., Inoshita, S., Mochida, Y., Kuroda, T. Sakamaki, K., Kuida, K., Yonehara, S., Ichijo, H., and Takeda, K. 2000. Execution of apoptosis signal-regulating kinase 1 (ASK1)-induced apoptosis by the mitochondria-dependent caspase activation. J. Biol. Chem. 275: 26576-26581.

Hirabayashi, M., Inoue, K., Tanaka, K., Nakadate, K., Ohsawa Y., Kamei, Y., Popiel, A.H., Sinohara, A., Iwamatsu, A., Kimura, Y., et al. 2001. VCP/p97 in abnormal protein aggregates, cytoplasmic vacuoles, and cell death, phenotypes relevant to neurodegeneration. Cell Death Differ. 8: 977-984.

Ichijo, H., Nishida, E., Irie, K., ten Dijke, P., Saitoh, M., Moriguchi, T., Takagi, M., Matsumoto, K., Miyazono, K., and Gotoh, Y. 1997. Induction of apoptosis by ASK1, a mammalian MAPKKK that activates SAPK/JNK and p38 signaling pathways. Science 275: 90-94.

Ikeda, H., Yamaguchi, M., Sugai, S., Aze, Y., Narumiya, S., and Kakizuka, A. 1996. Expanded polyglutamine in the Machado-Joseph disease protein induces cell death in vitro and in vivo. Nat. Genet. 13: 196-202.

Imai, Y., Soda, M., Inoue, H., Hattori, N., Mizuno, Y., and Takahashi, R. 2001. An unfolded putative transmembrane polypeptide, which can lead to endoplasmic reticulum stress, is a substrate of Parkin. Cell 105: 891-902.

Iwawaki, T., Hosoda, A., Okuda, T., Kamigori, Y., NomuraFuruwatari, C., Kimata, Y., Tsuru, A., and Kohno, K. 2001 Translational control by the ER transmembrane kinase/ribonuclease IRE1 under ER stress. Nat. Cell Biol. 3: 158-164.

Jackson, G.R., Salecker, I., Dong, X., Yao, X., Arnheim, N., Faber, P.W., MacDonald, M.E., and Zipursky, S.L. 1998 Polyglutamine-expanded human huntingtin transgenes induce degeneration of Drosophila photoreceptor neurons. Neuron 21: 633-642.

Jana, N.R., Zemskov, E.A., Wang, G., and Nukina, N. 2001. Altered proteasomal function due to the expression of polyglutamine-expanded truncated $\mathrm{N}$-terminal huntingtin induces apoptosis by caspase activation through mitochondrial cytochrome c release. Hum. Mol. Genet 10: 1049-1059.

Johnson, A.E. and Haigh, N.G. 2000. The ER translocon and retrotranslocation: Is the shift into reverse manual or automatic? Cell 102: 709-712.

Johnston, J.A., Dalton, M.J., Gurney, M.E., and Kopito, R.R. 
2000. Formation of high molecular weight complexes of mutant $\mathrm{Cu}, \mathrm{Zn}$-superoxide dismutase in a mouse model for familial amyotrophic lateral sclerosis. Proc. Natl. Acad. Sci. 97: 12571-12576.

Kakizuka, A. 1998. Protein precipitation: A common etiology in neurodegenerative disorders? Trends Genet. 14: 396-402.

Katayama, T., Imaizumi, K., Sato, N., Miyoshi, K., Kudo, T., Hitomi, J., Morihara, T., Yoneda, T., Gomi, F., Mori, Y., et al. 1999. Presenilin-1 mutations downregulate the signalling pathway of the unfolded-protein response. Nat. Cell Biol. 1: 479-485.

Kaufman, R.J. 1999. Stress signaling from the lumen of the endoplasmic reticulum: Coordination of gene transcriptional and translational controls. Genes \& Dev. 13: 1211-1233.

Kazemi-Esfarjani, P. and Benzer, S. 2000. Genetic suppression of polyglutamine toxicity in Drosophila. Science 287: $1837-1840$.

Lin, X., Cummings, C.J., and Zoghbi, H.Y. 1999. Expanding our understanding of polyglutamine diseases through mouse models. Neuron 24: 499-502.

Liu, C.Y., Schroder, M., and Kaufman, R.J. 2000. Ligand-independent dimerization activates the stress response kinases IRE1 and PERK in the lumen of the endoplasmic reticulum. J. Biol. Chem. 275: 24881-24885.

McCampbell, A. and Fischbeck, K.H. 2001. Polyglutamine and CBP: Fatal attraction? Nat. Med. 7: 528-530.

Nakagawa, T., Zhu, H., Morishima, N., Li, E., Xu, J., Yankner, B.A., and Yuan, J. 2000. Caspase-12 mediates endoplasmicreticulum-specific apoptosis and cytotoxicity by amyloid- $\beta$. Nature 403: 98-103.

Nishitoh, H., Saitoh, M., Mochida, Y., Takeda, K., Nakano, H., Rothe, M., Miyazono, K., and Ichijo, H. 1998. ASK1 is essential for JNK/SAPK activation by TRAF2. Mol. Cell 2: 389395.

Nucifora, Jr., F.C., Sasaki, M., Peters, M.F., Huang, H., Cooper, J.K., Yamada, M., Takahashi, H., Tsuji, S., Troncoso, J., Dawson, V.L., et al. 2001. Interference by huntingtin and atrophin-1 with cbp-mediated transcription leading to cellular toxicity. Science 291: 2423-2428.

Orr, H.T. 2001. Beyond the Qs in the polyglutamine diseases. Genes \& Dev. 15: 925-932.

Paulson, H.L., Perez, M.K., Trottier, Y., Trojanowski, J.Q., Subramony, S.H., Das, S.S., Vig, P., Mandel, J.L., Fischbeck, K.H., and Pittman, R.N. 1997. Intranuclear inclusions of expanded polyglutamine protein in spinocerebellar ataxia type 3. Neuron 19: 333-344.

Paulson, H.L., Bonini, N.M., and Roth, K.A. 2000. Polyglutamine disease and neuronal cell death. Proc. Natl. Acad. Sci. 97: 12957-12958.

Qiu, J.H., Asai, A., Chi, S., Saito, N., Hamada, H., and Kirino, T. 2000. Proteasome inhibitors induce cytochrome c-caspase3 -like protease-mediated apoptosis in cultured cortical neurons. J. Neurosci. 20: 259-265.

Sadoul, R., Fernandez, P.A., Quiquerez, A.L., Martinou, I., Maki, M., Schroter, M., Becherer, J.D., Irmler, M., Tschopp, J., and Martinou, J.C. 1996. Involvement of the proteasome in the programmed cell death of NGF-deprived sympathetic neurons. EMBO J. 15: 3845-3852.

Saitoh, M., Nishitoh, H., Fujii, M., Takeda, K., Tobiume, K., Sawada, Y., Kawabata, M., Miyazono, K., and Ichijo, H. 1998. Mammalian thioredoxin is a direct inhibitor of apoptosis signal-regulating kinase (ASK) 1. EMBO J. 17: 2596-2606.

Satyal, S.H., Schmidt, E., Kitagawa, K., Sondheimer, N., Lindquist, S., Kramer, J.M., and Morimoto, R.I. 2000. Polyglutamine aggregates alter protein folding homeostasis in Caenorhabditis elegans. Proc. Natl. Acad. Sci. 97:
$5750-5755$.

Sherman, M.Y. and Goldberg, A.L. 2001. Cellular defenses against unfolded proteins: A cell biologist thinks about neurodegenerative diseases. Neuron 29: 15-32.

Tobiume, K., Matsuzawa, A., Takahashi, T., Nishitoh, H., Morita, K., Takeda, K., Minowa, O., Miyazono, K., Noda, T., and Ichijo, H. 2001. ASK1 is required for sustained activations of JNK/p38 MAP kinases and apoptosis. EMBO Rep. 2: $222-228$.

Tobiume, K., Saitoh, M., and Ichijo, H. 2002. Activation of ASK1 by the stress-induced activating phosphorylation of pre-formed oligomer. J. Cell. Physiol. 191: 95-104.

Urano, F., Bertolotti, A., and Ron, D. 2000a. IRE1 and efferent signaling from the endoplasmic reticulum. I. Cell Sci. 113: 3697-3702.

Urano, F., Wang, X., Bertolotti, A., Zhang, Y., Chung, P., Harding, H.P., and Ron, D. 2000b. Coupling of stress in the ER to activation of JNK protein kinases by transmembrane protein kinase IRE1. Science 287: 664-666.

Waelter, S., Boeddrich, A., Lurz, R., Scherzinger, E., Lueder, G., Lehrach, H., and Wanker, E.E. 2001. Accumulation of mutant huntingtin fragments in aggresome-like inclusion bodies as a result of insufficient protein degradation. Mol. Biol. Cell 12: 1393-1407.

Warrick, J.M., Chan, H.Y., Gray-Board, G.L., Chai, Y., Paulson, H.L., and Bonini, N.M. 1999. Suppression of polyglutaminemediated neurodegeneration in Drosophila by the molecular chaperone HSP70. Nat. Genet. 23: 425-428.

Yamamoto, A., Lucas, J.J., and Hen, R. 2000. Reversal of neuropathology and motor dysfunction in a conditional model of Huntington's disease. Cell 101: 57-66.

Yang, D.D., Kuan, C.Y., Whitmarsh, A.J., Rincon, M., Zheng, T.S., Davis, R.J., Rakic, P., and Flavell, R.A. 1997. Absence of excitotoxicity-induced apoptosis in the hippocampus of mice lacking the Jnk3 gene. Nature 389: 865-870.

Yasuda, S., Inoue, K., Hirabayashi, M., Higashiyama, H., Yamamoto, Y., Fuyuhiro, H., Komure, O., Tanaka, F., Sobue, G., Tsuchiya, K., et al. 1999. Triggering of neuronal cell death by accumulation of activated SEK1 on nuclear polyglutamine aggregations in PML bodies. Genes Cells 4: 743-756.

Ye, Y., Meyer, H.H., and Rapoport, T.A. 2001. The AAA ATPase Cdc48/p97 and its partners transport proteins from the ER into the cytosol. Nature 414: 652-656.

Yuasa, T., Ohno, S., Kehrl, J.H., and Kyriakis, J.M. 1998. Tumor necrosis factor signaling to stress-activated protein kinase (SAPK)/Jun NH2-terminal kinase (JNK) and p38. Germinal center kinase couples TRAF2 to mitogen-activated protein kinase/ERK kinase kinase 1 and SAPK while receptor interacting protein associates with a mitogen-activated protein kinase kinase kinase upstream of MKK6 and p38. J. Biol. Chem. 273: 22681-22692. 


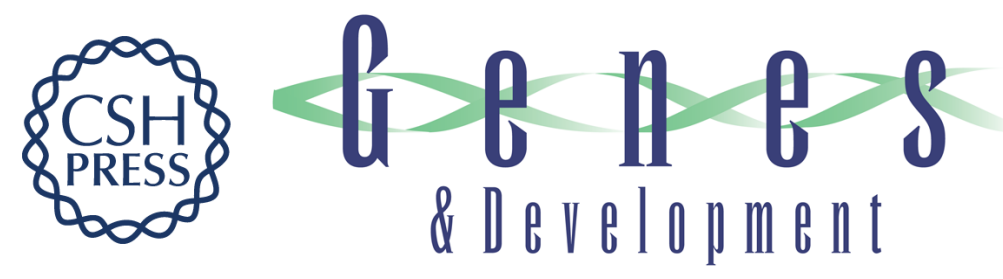

\section{ASK1 is essential for endoplasmic reticulum stress-induced neuronal cell death triggered by expanded polyglutamine repeats}

Hideki Nishitoh, Atsushi Matsuzawa, Kei Tobiume, et al.

Genes Dev. 2002, 16:

Access the most recent version at doi:10.1101/gad.992302

References

This article cites 47 articles, 21 of which can be accessed free at: http://genesdev.cshlp.org/content/16/11/1345.full.html\#ref-list-1

License

Email Alerting

Receive free email alerts when new articles cite this article - sign up in the box at the top Service right corner of the article or click here.

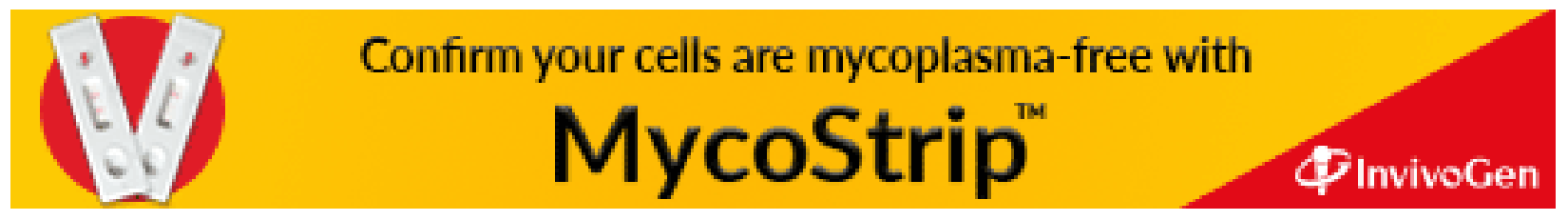

